\title{
TEMPO E TEMPERATURA EM REFEIÇÕES TRANSPORTADAS
}

Time and temperature in transported meals

Tiempo y temperatura en las comidas transportadas.

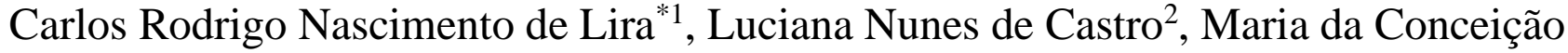 Pereira da Fonseca ${ }^{3}$}

${ }^{1}$ Mestrando da Pós-Graduação em Alimentos, Nutrição e Saúde da Escola de Nutrição da Universidade Federal da Bahia, Salvador-Bahia, Brasil.

${ }^{2}$ Especialista em Saúde da Família pelo Programa Estadual de Residência Multiprofissional Regionalizado em Saúde da Família e Pós graduada em Gestão de Unidades de Alimentação e Nutrição, Salvador-Bahia, Brasil.

${ }^{3}$ Docente do departamento de Ciências dos Alimentos da Escola de Nutrição da Universidade Federal da Bahia, Salvador-Bahia, Brasil.

*Correspondência: Escola de Nutrição da Universidade Federal da Bahia. Av. Araújo Pinho no 32 - Canela, Salvador-Bahia.CEP: 40110-090.Tel.: (071) 3283-7700.E-mail: carlos.rodrigo.n@ hotmail.

\section{RESUMO}

Analisar o binômio tempo-temperatura na produção de refeições transportadas foi o objetivo deste estudo. Para tal, o mesmo foi realizado em períodos distintos nas cinco fases de produção das refeições transportadas, sendo controlado o tempo e temperatura dos alimentos e equipamentos utilizados para armazenamento e distribuição das refeições. As técnicas de aferição seguiram o recomendado pelo manual de boas práticas de manipulação de alimentos. As análises utilizadas foram: frequência simples e absoluta para identificar a proporção de desvios de temperatura; teste McNemar para comparação dos períodos e para avaliar as frequências de temperatura; $t$-teste para verificar se houve diferença estatística nas temperaturas médias dos equipamentos. Desta forma, foi identificado que na cadeia fria, em ambos os períodos estudados, houve diferença significativa na temperatura do suco e sobremesa. As saladas obtiveram $100 \%$ de inadequações de temperatura da produção até a recepção. Na cadeia aquecida, a média de temperatura nas fases da produção, espera, envase e distribuição, as preparações estavam acima de $60^{\circ} \mathrm{C}$. Na recepção da carga a média de temperatura estava abaixo de $60^{\circ} \mathrm{C}$ para a guarnição, prato principal e opção no primeiro período do estudo. Assim, houve inconformidade nas temperaturas dos alimentos em todo ciclo produtivo, mesmo com pequenas melhorias.

Palavras-chave: Serviço de Alimentação. Inspeção de Alimentos. Inocuidade dos Alimentos.

\section{ABSTRACT}

Analyzing time-temperature binomial in the production of transported meals was the objective of this study. To this end, was carried out at different times in the five stages of production of the transported meals, being controlled the time and temperature of the food and equipment used for storage and distribution of meals. The measurement techniques followed the recommended by the manual of good food handling practices. The analyzes used were: simple and absolute frequency to identify the proportion of temperature deviations; McNemar test to compare periods and to evaluate temperature frequencies; $t$-test to verify if there was a statistical difference in the average temperatures of the equipment. Thus, it was identified that in the cold chain, in both periods studied, there was a significant difference in the temperature of juice and dessert. The salads had 100\% of temperature inadequacies from production to reception. In the heated chain, the average temperature in the production, waiting, filling and distribution phases, the preparations were above $60^{\circ} \mathrm{C}$. At load reception the average temperature was below $60^{\circ} \mathrm{C}$ 
for garnish, main course and option in the first period of the study. Thus, there was nonconformity in food temperatures throughout the production cycle, even with minor improvements.

Keywords: Food Services. Food Inspection. Food Safety.

\section{RESUMEN}

El objetivo este estudio fue analizar el binomio tiempo-temperatura en la producción de comidas transportadas. Con este fin, se llevó a cabo en diferentes momentos en cinco etapas de producción de las comidas transportadas, controlando el tiempo y la temperatura de los alimentos y equipos para el almacenamiento y distribución de las comidas. Las técnicas de medición siguieron lo recomendado por el manual de buenas prácticas de manipulación de alimentos. Los análisis fueron: frecuencia simple y absoluta para desviaciones de temperatura; Prueba de McNemar para comparar períodos y frecuencias de temperatura; Prueba t para verificar diferencia estadística en las temperaturas promedio del equipo. En ambos periodos, hubo una diferencia significativa en la temperatura del jugo y postre. Las ensaladas tenían 100\% de las deficiencias de temperatura desde la producción hasta recepción. En la cadena calentada, la temperatura promedio en las fases de producción, espera, llenado y distribución, las preparaciones fueron superiores a $60^{\circ} \mathrm{C}$. En la recepción de la carga, la temperatura promedio fue inferior a $60^{\circ} \mathrm{C}$ para la guarnición, plato principal y opción en el primer período del estudio. No hubo conformidad en las temperaturas de los alimentos durante todo el ciclo de producción, incluso con mejoras menores.

Descriptores: Servicios de Alimentación. Inspección de Alimentos. Inocuidad de los Alimentos.

\section{INTRODUÇÃO}

Segundo a Associação Brasileira das Empresas de Refeições Coletivas - ABERC (ABERC, 2015), são fornecidas diariamente 11,8 milhões de refeições pelos restaurantes que as produzem em Unidades de Alimentação e Nutrição (UAN). Diante disto, é importante implantar métodos capazes de controlar a qualidade das refeições em suas diversas dimensões, tais como controle higiênico-sanitário, controle de temperatura, nutricional e sensorial (SILVA JR., 2014; ABREU; SPINELLI; PINTO, 2016).

Entre as modalidades de distribuição de refeições em UAN, a refeição transportada caracteriza-se pela produção em um local e distribuição em outro, permitindo deste modo o fornecimento de refeições onde não há estrutura apropriada para sua produção, podendo determinar menor custo com equipamentos e mão-de-obra. Essa modalidade de refeições envolve maiores riscos a Segurança Alimentar (SA), tendo em vista um maior tempo envolvido entre a produção e o consumo das refeições (SILVA JR., 2014).
Adoção de medidas que visem promover e proteger a saúde dos comensais é de suma importância nestas Unidades, além disso, fiscalizar e inspecionar os alimentos para consumo humano são recomendações que estão entre o campo de atuação do Sistema Único de Saúde conforme deliberado na lei $\mathrm{n}^{\circ}$ 8.080 de 1990.

Consequentemente o controle do tempo e temperatura é uma medida eficaz na SA. Segundo a Organização Mundial de Saúde, a alta temperatura contribui para a garantia da inocuidade dos alimentos, porém ressalta-se que quanto maior o tempo de exposição dos alimentos na zona de perigo (entre $10^{\circ} \mathrm{C}$ e $60^{\circ} \mathrm{C}$ ), maior o risco de sobrevivência e multiplicação das bactérias patogênicas e os microrganismos produtores de toxinas, propiciando assim a ocorrência de Doenças Veiculadas por Alimentos (DVA) que tem sua origem em procedimentos inadequados e se desenvolvem por múltiplas falhas relacionadas aos hábitos dos funcionários, à utilização de matérias-primas de má qualidade e condições precárias de produção (MARINHO et al., 2015). Por isso um rígido controle 
das condições higiênico-sanitárias e do binômio tempo e temperatura são importantes, sobretudo, em refeições transportadas.

Assim, o objetivo deste estudo é analisar o binômio tempo-temperatura em períodos distintos do processo de produção de refeições transportadas.

\section{MATERIAIS E MÉTODOS}

Estudo realizado na Unidade de Alimentação e Nutrição do Restaurante Universitário de uma universidade federal de um município baiano o qual funciona sob a modalidade de terceirização, sendo este serviço do tipo administração de cozinha e refeições transportadas. Diariamente, transportam-se aproximadamente 300 refeições para uma das Residências Universitária, situada em bairro distante da Unidade produtora.

A coleta dos dados foi efetuada em dois momentos: em agosto de 2014 e após mudanças operacionais e de equipamentos no serviço, realizouse nova coleta em outubro de 2015 . Os estudos foram antecedidos por estudo piloto realizados por estudantes do curso de Nutrição e integrantes do Grupo de Pesquisa e Extensão do Restaurante Universitário (GPERU), previamente treinados para este fim. As aferições de temperatura foram realizadas em cada etapa do ciclo de produção das refeições transportadas: término da cocção, envase dos alimentos, armazenamento nos carros, recepção da refeição no ponto de distribuição e durante a distribuição.

O monitoramento do tempo foi iniciado no momento que se iniciou a cocção, e finalizado até 2 horas após o início da distribuição. As temperaturas dos equipamentos usados para armazenamento (passthrough, gastronorm e balcão térmico) e dos alimentos armazenados nestes, também foram verificadas e registradas.

Foram utilizados termômetros de haste de aço inoxidável, digital da marca Minipa, com faixa de medição $-10^{\circ} \mathrm{C}$ a $200^{\circ} \mathrm{C}$ com precisão de $2^{\circ} \mathrm{C}$ e termômetro a laser da marca Fluke 62 MINI-IR com alcance de -30 à $500^{\circ} \mathrm{C}$. Utilizou-se a técnica recomendado pelo Manual ABERC (2015) e Manual de boas práticas de manipulação de alimentos (SÃO PAULO, 2016). No caso de sobremesas como frutas e doces, foi aferida a temperatura em suas superfícies com termômetro a laser.

Para aferição de temperatura dos passthroughs foram realizadas duas medidas: do equipamento e do alimento contido neste, sendo realizados com termômetro a laser. Diante da não observância de valores de recomendação direta de temperaturas para os pass-throughs, foi também utilizada como parâmetro de adequação às temperaturas do termo de referência da Universidade com a empresa terceirizada.

No balcão térmico eram realizadas três medidas, sendo duas nas laterais e uma no centro do equipamento, considerando-se o valor médio. O balcão de distribuição na unidade distribuidora era ligado $1 \mathrm{~h}$ antes de receber os gastronorm, para que ao receber, eles já estivessem em temperatura ideal para acondiciona-los e esta adequação era atestada com a aferição dos balcões antes de montá-los com as preparações.

Ao chegarem à Unidade distribuidora os gastronorm eram retirados do veículo e acomodados no balcão de distribuição. Após esse processo, os alimentos tinham sua temperatura aferida com termômetro de haste e esta aferição repetia-se duas horas após iniciar a distribuição. 
No Quadro 1 estão indicadas as temperaturas e o tempo recomendado para o controle dos alimentos de acordo com o termo de referência da Universidade com a empresa terceirizada, a Resolução da Diretoria Colegiada - RDC no 216 (BRASIL, 2004) e da Portaria do Centro de Vigilância Sanitária - CVS 05 (SÃO PAULO, 2013) que foram usadas neste estudo como parâmetros de análises de conformidades ou inconformidades.

A tabulação dos dados foi realizada no programa Microsoft Excel@ versão 2010, utilizando frequência simples e absoluta, para identificar a proporção de desvios de inadequação ou não de temperatura conforme a RDC n²16/04 e CVS 05/2013. Para a comparação dos períodos analisados no estudo foi utilizado o teste McNemar, para avaliar as frequências de temperaturas em conformidade ou não. Para este teste foi utilizado a estatística de teste qui-quadrado, como também o cálculo dos resíduos padronizados (Zres). Dessa forma, foi possível verificar diferenças estatisticamente significativas entre as variáveis estudadas.

$\mathrm{O} \mathrm{Z}$ res é útil em uma análise mais detalhada de cada uma das variáveis consideradas na estatística de teste qui-quadrado, ou seja, pelo cálculo dos resíduos padronizados é possível verificar se a temperatura observada é diferente da esperada (Zres de + ou $-1,96)$ no intervalo de temperatura recomendado para a preparação.

Também foi usado o $t$-teste para verificar nos dois períodos analisados se houve diferença estatística nas temperaturas médias dos equipamentos usados para armazenamento das refeições. Todos os testes foram realizados no IBM SPSS Statistics 21.0 e adotado nível de significância de 5\%.

Quadro 1. Critério de tempo e temperatura utilizado como referência no estudo, para etapas do processo produtivo e temperatura para equipamentos usados na UAN. Salvador, 2014-2015.

\begin{tabular}{|c|c|c|c|c|}
\hline \multirow{2}{*}{ PROCEDIMENTO } & \multicolumn{2}{|c|}{ CADEIA AQUECIDA } & \multicolumn{2}{c|}{ CADEIA RERIGERADA } \\
\cline { 2 - 5 } & Tempo de exposição & $\begin{array}{c}\text { Temperatura } \\
\text { recomendada }\end{array}$ & Tempo de exposição & $\begin{array}{c}\text { Temperatura } \\
\text { recomendada }\end{array}$ \\
\hline \multirow{2}{*}{ Envase } & 6 Horas & $60^{\circ} \mathrm{c}$ & 4 Horas & $10^{\circ} \mathrm{C}$ \\
\cline { 2 - 5 } Recebimento & $1 \mathrm{Hora}$ & $<60^{\circ} \mathrm{c}$ & $2 \mathrm{Horas}$ & Entre $10^{\circ} \mathrm{C} \mathrm{e} 21^{\circ} \mathrm{C}$ \\
\cline { 2 - 5 } & $6 \mathrm{Horas}$ & $60^{\circ} \mathrm{c}$ & $4 \mathrm{Horas}$ & $10^{\circ} \mathrm{C}$ \\
\hline $\begin{array}{c}\text { Armazenamento no } \\
\text { pass-throughs }\end{array}$ & $1 \mathrm{Hora}$ & $<60^{\circ} \mathrm{c}$ & $2 \mathrm{Horas}$ & Entre $10^{\circ} \mathrm{C} \mathrm{e} 21^{\circ} \mathrm{C}$ \\
\hline $\begin{array}{c}\text { Armazenamento no } \\
\text { balcão de distribuição }\end{array}$ & - & $>65^{\circ} \mathrm{C}$ & - & $10^{\circ} \mathrm{C}$ \\
\hline $\begin{array}{c}\text { Armazenamento } \\
\text { no refrigerador }\end{array}$ & - & $80 \mathrm{a} 90^{\circ} \mathrm{C}$ & - & $8^{\circ} \mathrm{C}$ \\
\hline
\end{tabular}

Fonte: Adaptado do contrato da Universidade em estudo e das recomendações da RDC n 216/04 e da Portaria CVS 05/2013.

\section{RESULTADOS E DISCUSSÃO}

Os cardápios analisados durante os dois períodos do estudo eram compostos por nove preparações, servidas diariamente, totalizando 135 preparações estudadas: entrada (duas saladas cruas), acompanhamento (arroz e feijão), guarnição, prato principal, opção ovolactovegetariana, bebida não alcoólica (suco) e sobremesa.

Nas preparações da cadeia fria observou-se variação na média das temperaturas em todo processo produtivo nos dois períodos estudado variando de $7,48^{\circ} \mathrm{C}(1,34$ desvios padrão - $\mathrm{Dp})$ a $26,26^{\circ} \mathrm{C}(8,44$ $\mathrm{Dp})$. $\mathrm{O}$ teste qui-quadrado indicou diferença 
significativa na temperatura da sobremesa $(p=0,024) \mathrm{e}$ suco $(p=0,000)$, não estando estão em conformidade com o preconizado pela literatura (SÃO PAULO, 2013), algo que se observou em ambos os períodos do estudo, sendo refletido principalmente na etapa de produção e distribuição (Tabela 1).

Dentre os alimentos verificados, as saladas apresentaram maior inconformidade quanto à temperatura, apresentando $100 \%$ de inadequação, desde o processo de produção até o momento da recepção na unidade distribuidora, tanto no estudo de 2014 quanto no de 2015. Observa-se desta forma que, para além da inconformidade com o que traz a legislação, a UAN não obteve êxito nas intervenções realizadas para corrigir o problema.

$\mathrm{Na}$ UAN avaliada foi observado que o preparo das saladas servidas no jantar começava ainda no período da manhã. Além disso, as preparações eram montadas e aguardavam a finalização de todo o lote para serem cobertas por fita filme de PVC e acondicionadas no refrigerador, prolongando assim o tempo de exposição à temperatura ambiente. Sendo estes os fatores contribuintes para a inconformidade encontrada.

Tabela 1. Distribuição percentual das faixas de temperaturas da cadeia fria de refeições transportadas para o Restaurante Universitário em estudo. Agosto de 2014 ( $1^{\circ}$ período) e outubro de 2015 ( $2^{\circ}$ período).

\begin{tabular}{|c|c|c|c|c|c|c|c|c|c|}
\hline \multirow{3}{*}{$\begin{array}{c}\text { Ciclo } \\
\text { pro } \\
\text { dutivo }\end{array}$} & \multirow{3}{*}{ Análise } & \multirow{2}{*}{\multicolumn{2}{|c|}{$\begin{array}{l}\text { Salada } 1 \\
\text { Período } \\
\end{array}$}} & \multirow{2}{*}{\multicolumn{2}{|c|}{$\begin{array}{c}\text { Salada } 2 \\
\text { Período } \\
\end{array}$}} & \multirow{2}{*}{\multicolumn{2}{|c|}{$\begin{array}{c}\text { Sobremesa } \\
\text { Período }\end{array}$}} & \multirow{2}{*}{\multicolumn{2}{|c|}{$\frac{\text { Suco }}{\text { Período }}$}} \\
\hline & & & & & & & & & \\
\hline & & $1^{\circ}$ & $2^{\circ}$ & $1^{\circ}$ & $2^{\circ}$ & $1^{\circ}$ & $2^{\circ}$ & $1^{\circ}$ & $\mathbf{2}^{\circ}$ \\
\hline \multirow{6}{*}{ 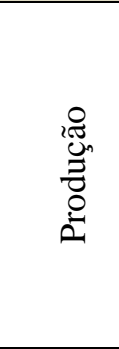 } & $\mathrm{N}^{0}$ total de aferições & 5 & 10 & 5 & 10 & 5 & 8 & 5 & 10 \\
\hline & $\begin{array}{l}\% \text { de temperatura } \\
\leq 10^{\circ} \mathrm{c}^{\mathrm{b}+(4,3)}\end{array}$ & 0 & 0 & 0 & 0 & 20 & 0 & 0 & 80 \\
\hline & $\begin{array}{c}\% \text { de temperatura } \\
>10^{\circ} \mathrm{c}^{\mathrm{b}-(4,3)}\end{array}$ & 100 & 100 & 100 & 100 & 80 & 100 & 100 & 20 \\
\hline & Média & 21,72 & 23,62 & 24,35 & 24,36 & 22,36 & 26,26 & 16,52 & 9,49 \\
\hline & Desvio padrão & 1,40 & 4,38 & 1,34 & 2,99 & 8,44 & 1,26 & 2,45 & 4,93 \\
\hline & Mediana & 22 & 24,80 & 24,35 & 26 & 25,80 & 26,50 & 16,80 & 7,70 \\
\hline \multirow{6}{*}{ 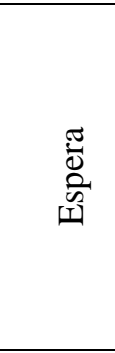 } & $\mathrm{N}^{0}$ total de aferições & 5 & 10 & 5 & 10 & 5 & 8 & 5 & 10 \\
\hline & $\begin{array}{c}\% \text { de temperatura } \\
\leq 10^{\circ} \mathrm{c}\end{array}$ & 0 & 0 & 0 & 0 & 20 & 0 & 0 & 80 \\
\hline & $\begin{array}{c}\% \text { de temperatura } \\
>10^{\circ} \mathrm{C}\end{array}$ & 100 & 100 & 100 & 100 & 80 & 100 & 100 & 20 \\
\hline & Média & 21,72 & 20,31 & 24,35 & 21,15 & 22,36 & 25,34 & 16,52 & 7,48 \\
\hline & Desvio padrão & 1,40 & 3,57 & 1,34 & 3,61 & 8,44 & 1,63 & 2,45 & 3,95 \\
\hline & Mediana & 22 & 19,80 & 24,35 & 22,50 & 25,80 & 25,55 & 16,80 & 6,30 \\
\hline \multirow{6}{*}{ 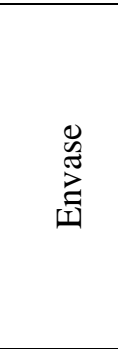 } & $\mathrm{N}^{0}$ total de aferições & 5 & 10 & 5 & 10 & 5 & 8 & 5 & 10 \\
\hline & $\begin{array}{c}\% \text { de temperatura } \\
\leq 10^{\circ} \mathrm{c}\end{array}$ & 0 & 0 & 0 & 0 & 20 & 0 & 0 & 70 \\
\hline & $\begin{array}{c}\% \text { de temperatura } \\
>10^{\circ} \mathrm{C}\end{array}$ & 100 & 100 & 100 & 100 & 80 & 100 & 100 & 30 \\
\hline & Média & 21,90 & 20,43 & 23,45 & 20,51 & 22,36 & 25,95 & 16,52 & 8,57 \\
\hline & Desvio padrão & 1,69 & 3,29 & 0,07 & 3,14 & 8,44 & 1,90 & 2,45 & 3,10 \\
\hline & Mediana & 22 & 20,90 & 23,45 & 20,65 & 25,80 & 26,10 & 16,80 & 7,20 \\
\hline \multirow{6}{*}{ 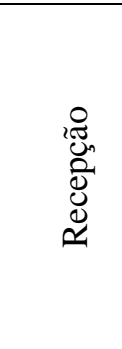 } & $\mathrm{N}^{0}$ total de aferições & 5 & 10 & 5 & 10 & 5 & 8 & 5 & 10 \\
\hline & $\begin{array}{c}\% \text { de temperatura } \\
\leq 10^{\circ} \mathrm{c}\end{array}$ & 0 & 0 & 0 & 0 & 0 & 0 & 0 & 60 \\
\hline & $\begin{array}{c}\% \text { de temperatura } \\
>10^{\circ} \mathrm{C}\end{array}$ & 100 & 100 & 100 & 100 & 100 & 100 & 100 & 40 \\
\hline & Média & 19,80 & 18,07 & 21,00 & 21,14 & 21,94 & 24,30 & 17,50 & 10,21 \\
\hline & Desvio padrão & 2,36 & 2,50 & 1,41 & 4,35 & 6,15 & 1,91 & 1,92 & 2,76 \\
\hline & Mediana & 19 & 17,85 & 21,00 & 22,40 & 24,40 & 24,15 & 18,40 & 9,40 \\
\hline
\end{tabular}




\begin{tabular}{|c|c|c|c|c|c|c|c|c|c|}
\hline \multirow{6}{*}{ 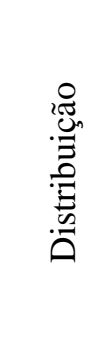 } & $\mathrm{N}^{0}$ total de aferições & 15 & 30 & 15 & 30 & 15 & 29 & 15 & 30 \\
\hline & $\begin{array}{c}\% \text { de temperatura } \\
\leq 10^{\circ} \mathrm{c}\end{array}$ & 6,67 & 0 & 0 & 0 & 0 & 0 & 0 & 33,33 \\
\hline & $\begin{array}{c}\% \text { de temperatura } \\
>10^{\circ} \mathrm{c}\end{array}$ & 93,33 & 100 & 100 & 100 & 100 & 100 & 100 & 66,67 \\
\hline & Média & 17,72 & 20,48 & 19,57 & 20,80 & 23,40 & 23,56 & 18,18 & 12,26 \\
\hline & Desvio padrão & 3,82 & 2,05 & 5,71 & 3,61 & 1,95 & 1,24 & 2,08 & 3,80 \\
\hline & Mediana & 17,40 & 20,65 & 20 & 22,10 & 24,20 & 23,50 & 18,90 & 10,95 \\
\hline \multicolumn{2}{|c|}{$\begin{array}{l}\text { Valor de } \mathrm{P} \chi 2 \text { - Elementos do } \\
\text { cardápio }\end{array}$} & \multicolumn{2}{|c|}{0,157} & \multicolumn{2}{|c|}{0} & \multicolumn{2}{|c|}{$0,024^{\mathrm{a}}$} & \multicolumn{2}{|c|}{$0,000^{\mathrm{a}}$} \\
\hline \multicolumn{2}{|c|}{$\begin{array}{c}\text { Valor de } \mathrm{P} \chi 2-\text { Processo } \\
\text { produtivo }\end{array}$} & \multicolumn{8}{|c|}{$0,000^{\mathrm{a}}$} \\
\hline Tota & $\mathrm{N}^{0}$ total de aferições & 35 & 70 & 35 & 70 & 40 & 61 & 35 & 70 \\
\hline
\end{tabular}

Faixa de temperatura segue as recomendações da CVS 5/2013, para conformidade e inconformidade. Quando aparecer a letra $\mathrm{a}=$ teste Qui-quadrado significativo $(5 \%)$; $\mathrm{b}+$ resíduos padronizados (Zres), valor positivo $\geq+1,96$; $\mathrm{b}$ resíduos padronizados (Zres), valor negativo $\leq-1,96$, ou seja, nível de significância de 5\%.

O tempo médio do momento do preparo até a distribuição ultrapassou o tempo recomendado (SÃO PAULO, 2013) no primeiro período do estudo para a salada 1. No segundo período houve diminuição do tempo dispendido para a produção de todos os alimentos da cadeia refrigerada (Quadro 2).

Quadro 2. Tempo médio dispendido da produção ao recebimento de acordo com os elementos do cardápio das preparações transportadas. Agosto de 2014 ( $\left(1^{\circ}\right.$ período $)$ e outubro de 2015 ( $1^{\circ}$ período).

\begin{tabular}{|c|c|c|}
\hline \multicolumn{3}{|c|}{ CADEIA REFRIGERADA } \\
\hline PREPARAÇÕES & 10 PERÍODO & 20 PERÍODO \\
\hline Salada 1 & $03 \mathrm{~h} 24 \mathrm{~min}$ & $02 \mathrm{~h} 50 \mathrm{~min}$ \\
\hline Salada 2 & $04 \mathrm{~h} 11 \mathrm{~min}$ & $02 \mathrm{~h} 23 \mathrm{~min}$ \\
\hline Sobremesa & $02 \mathrm{~h} 36 \mathrm{~min}$ & $01 \mathrm{~h} 20 \mathrm{~min}$ \\
\hline Suco & $01 \mathrm{~h} 08 \mathrm{~min}$ & $01 \mathrm{~h} 52 \mathrm{~min}$ \\
\hline \multicolumn{3}{|c|}{ CADEIA AQUECIDA } \\
\hline PREPARAÇÕES & 1o PERÍODO & 20 PERÍODO \\
\hline Arroz & $03 \mathrm{~h} 50 \mathrm{~min}$ & $01 \mathrm{~h} 48 \mathrm{~min}$ \\
\hline Feijão & $02 \mathrm{~h} 04 \mathrm{~min}$ & $03 \mathrm{~h} 55 \mathrm{~min}$ \\
\hline Guarnição & $03 \mathrm{~h} 07 \mathrm{~min}$ & $02 \mathrm{~h} 18 \mathrm{~min}$ \\
\hline Prato principal & $03 \mathrm{~h} 23 \mathrm{~min}$ & $02 \mathrm{~h} 30 \mathrm{~min}$ \\
\hline Opção & $01 \mathrm{~h} 03$ min & $02 \mathrm{~h} 29 \mathrm{~min}$ \\
\hline
\end{tabular}

Diversos fatores podem ser apontados para estas inconformidades, entre as quais está o elevado tempo de exposição do alimento a temperatura ambiente durante o preparo; a climatização da área de pré-preparo não estava adequada contando ainda com grande fluxo de entrada e saída dos manipuladores no setor; elevado número de gastronorm armazenados no refrigerador e o número de vezes em que o equipamento era aberto. Assim, as saladas eram direcionadas para o balcão térmico com temperaturas acima de $10^{\circ} \mathrm{C}$, o que favorece o crescimento microbiano.

Os resultados observados nos dois períodos de estudo demonstram a necessidade de constantes treinamentos para os manipuladores e gestores, além da manutenção periódica dos equipamentos da UAN. 
Há necessidade de o responsável técnico do serviço rever o processo produtivo da salada, no sentido de diminuir o tempo que decorre entre o preparo e distribuição além de estabelecer meios para conseguir diminuir a temperatura da preparação em todo o ciclo produtivo.
Ainda, devem-se avaliar os equipamentos usados para armazenamento das preparações da cadeia fria, ao passo que foi identificado que os refrigeradores e balcão frio estavam com temperatura médias superiores as $13^{\circ} \mathrm{C}$ nos dois períodos de estudo, contribuindo, portanto, com os desvios de temperaturas observados (Gráfico 1).

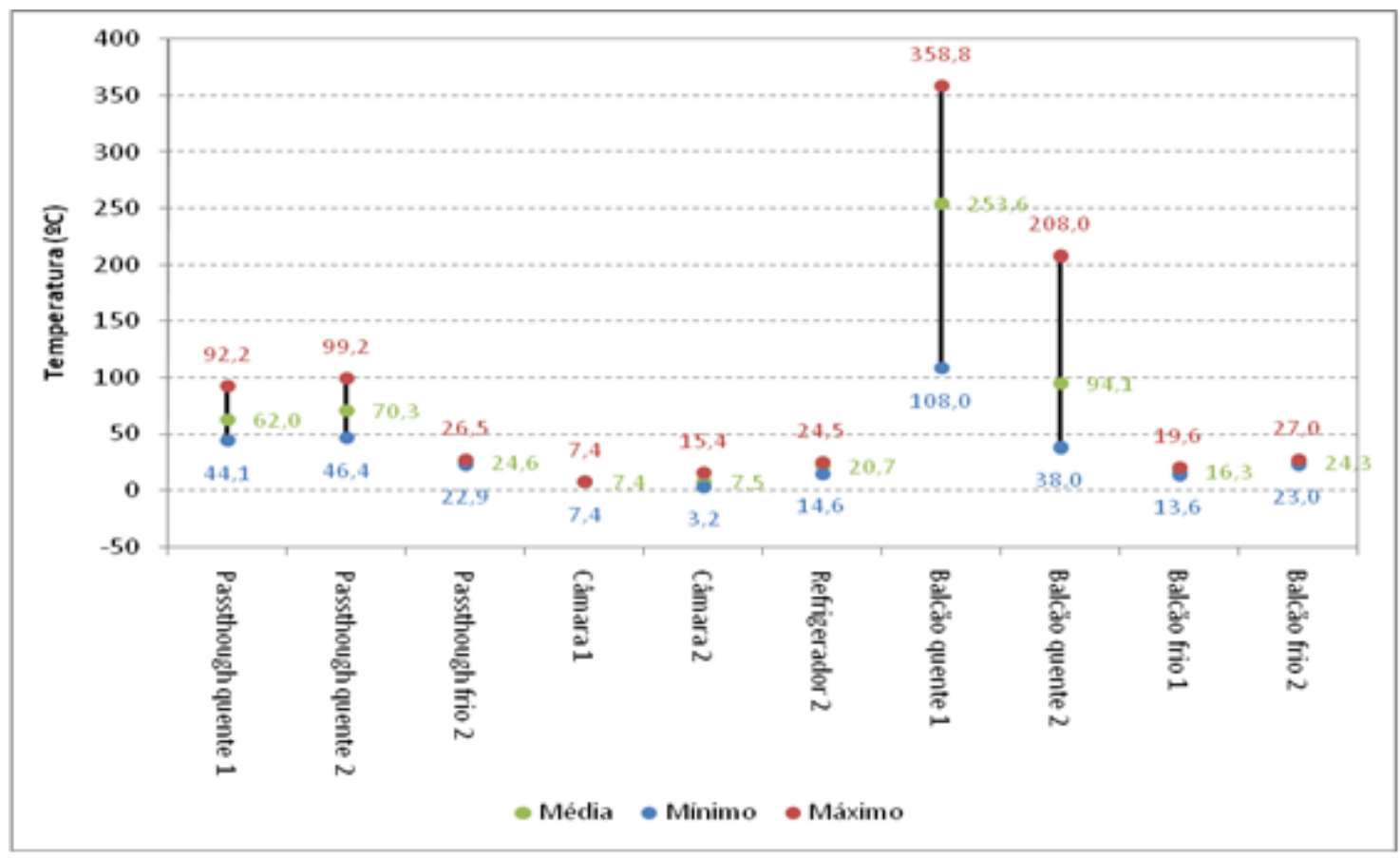

Gráfico 1. Temperatura dos equipamentos utilizados para armazenamento dos alimentos/preparações transportadas do Restaurante Universitário, em agosto de 2014 e outubro de 2015.

Resultados semelhantes foram encontrados por Borges et al., (2016) em uma pesquisa realizada em um restaurante de Palmas-Tocantins, onde foi verificado que os pratos frios apresentaram temperaturas entre 19,6 a $25,4^{\circ} \mathrm{C}$ no período do almoço e 18,4 a $25,8^{\circ} \mathrm{C}$ no período do jantar; por Wiethölter e Fassina (2017) onde em nenhum dos dias avaliados a temperatura das saladas esteve abaixo de $10^{\circ} \mathrm{C}(0 \%)$ em uma empresa situada no Rio Grande do Sul; e por Santos e Bassi (2015) onde as temperaturas das saladas apresentaram inconformidade no estudo realizado em UAN na cidade de São Paulo.
Neste estudo, a sobremesa e o suco foram os elementos da cadeia fria que indicaram diferenças significativas de temperatura acima de $10^{\circ} \mathrm{C}$ entre o primeiro e segundo período. Para a sobremesa, os valores do desvio padrão sugerem ocorrência de algumas falhas, como: erro de aferição da temperatura, equipamentos com defeito ou descalibrados.

Em relação à cadeia aquecida (Tabela 2), observou-se que na fase da espera para o envase, no envase, recepção da carga e distribuição das refeições, algumas preparações apresentaram inadequação de 
temperatura nos dois períodos analisados. $\mathrm{Na}$ espera para o envase e na fase do envase no primeiro período do estudo, a guarnição e o prato principal (PP) apresentam $60 \%$ de temperatura abaixo de $60^{\circ} \mathrm{C}$. Já na recepção da carga, também na primeira fase do estudo, os itens em inconformidade com a legislação foram à guarnição e a opção (80\%) e o PP (60\%). Quanto à distribuição, tanto a guarnição no primeiro momento $(86,67 \%)$ quanto à opção no segundo período $(73,33 \%)$ não conseguiram atingir a temperatura preconizada de no mínimo $60^{\circ} \mathrm{C}$.

Tabela 2. Distribuição percentual das faixas de temperaturas da cadeia aquecida de refeições transportadas para o Restaurante Universitário em estudo. Agosto de 2014 ( $1^{\circ}$ período) e outubro de 2015 ( $2^{\circ}$ período).

\begin{tabular}{|c|c|c|c|c|c|c|c|c|c|c|c|}
\hline \multirow{3}{*}{$\begin{array}{c}\text { Ciclo } \\
\text { produ } \\
\text { tivo }\end{array}$} & \multirow{3}{*}{$\begin{array}{l}\text { Variáveis de } \\
\text { análise }\end{array}$} & \multirow{2}{*}{\multicolumn{2}{|c|}{$\begin{array}{c}\text { Arroz } \\
\text { Período }\end{array}$}} & \multirow{2}{*}{\multicolumn{2}{|c|}{$\begin{array}{c}\text { Feijão } \\
\text { Período }\end{array}$}} & \multirow{2}{*}{\multicolumn{2}{|c|}{$\begin{array}{c}\text { Guarnição } \\
\text { Período } \\
\end{array}$}} & \multirow{2}{*}{\multicolumn{2}{|c|}{$\begin{array}{c}\text { Prato } \\
\text { Principal } \\
\text { Período } \\
\end{array}$}} & \multirow{2}{*}{\multicolumn{2}{|c|}{$\begin{array}{c}\text { Opção } \\
\text { Período }\end{array}$}} \\
\hline & & & & & & & & & & & \\
\hline & & $\mathbf{1}^{\circ}$ & $2^{\circ}$ & $\mathbf{1}^{\circ}$ & $2^{\circ}$ & $\mathbf{1}^{\circ}$ & $2^{\circ}$ & $1^{\circ}$ & $2^{\circ}$ & $\mathbf{1}^{\circ}$ & $2^{\circ}$ \\
\hline \multirow{6}{*}{ 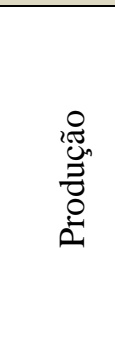 } & $\mathrm{N}^{0}$ total de aferições & 5 & 10 & 5 & 10 & 5 & 10 & 5 & 10 & 5 & 10 \\
\hline & $\begin{array}{l}\% \text { de temperatura } \\
<\operatorname{de~} 60^{\circ} \mathrm{c}^{\mathrm{b}+(2,8)}\end{array}$ & 0 & 0 & 0 & 0 & 20 & 40 & 40 & 10 & 20 & 20 \\
\hline & $\begin{array}{l}\% \text { de temperatura } \\
\geq \text { de } 60^{\circ} \mathrm{c}^{\mathrm{b}-(-2,8)}\end{array}$ & 100 & 100 & 100 & $\begin{array}{c}100,0 \\
0\end{array}$ & 80 & 60 & 60 & 90 & 80 & 80 \\
\hline & Média & 92,68 & 90,09 & 93,62 & 90,21 & 70,40 & 69,34 & 60,28 & 72,42 & 76 & 70,65 \\
\hline & Desvio padrão & 11,03 & 9,65 & 2,76 & 5,88 & 22,04 & 21,72 & 13,75 & 10,96 & 8,82 & 14,78 \\
\hline & Mediana & 97,50 & 89,65 & 92,80 & 90,65 & 68,70 & 74,45 & 57,90 & 73,85 & 76,70 & 70,15 \\
\hline \multirow{6}{*}{$\begin{array}{l}\frac{\pi}{0} \\
\frac{0}{n} \\
\text { In }\end{array}$} & $\mathrm{N}^{0}$ total de aferições & 5 & 10 & 5 & 10 & 5 & 10 & 5 & 10 & 5 & 10 \\
\hline & $\begin{array}{l}\% \text { de temperatura } \\
<\operatorname{de~} 60^{\circ} \mathrm{c}^{\mathrm{b}+(2,8)}\end{array}$ & 0 & 0 & 0 & 0 & 60 & 40 & 60 & 20 & 0 & 30 \\
\hline & $\begin{array}{l}\% \text { de temperatura } \\
\geq \text { de } 60^{\circ} \mathrm{c}^{\mathrm{b}-(-2,8)}\end{array}$ & 100 & 100 & 100 & 100 & 40 & 60 & 40 & 80 & 100 & 70 \\
\hline & Média & 92,68 & 76,81 & 93,62 & 86,27 & 51,26 & 70,18 & 60,28 & 69,32 & 76,00 & 68,75 \\
\hline & Desvio padrão & 11,03 & 7,93 & 2,76 & 4,06 & 15,49 & 16,33 & 13,75 & 12,40 & 8,82 & 9,59 \\
\hline & Mediana & 97,50 & & 92,80 & 87,30 & 44,10 & 72,80 & 57,90 & 70,45 & 76,70 & 72,85 \\
\hline \multirow{6}{*}{ 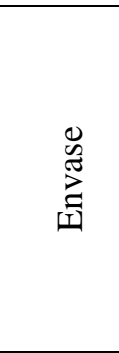 } & $\mathrm{N}^{0}$ total de aferições & 5 & 10 & 5 & 10 & 5 & 10 & 5 & 10 & 5 & 10 \\
\hline & $\begin{array}{l}\% \text { de temperatura } \\
<\operatorname{de~} 60^{\circ} \mathrm{c}^{\mathrm{b}+(2,8)}\end{array}$ & 0 & 0 & 0 & 0 & 60 & 20 & 60 & 10 & 0 & 20 \\
\hline & $\begin{array}{l}\% \text { de temperatura } \\
\geq \text { de } 60^{\circ} \mathrm{c}^{\mathrm{b}-(-2,8)}\end{array}$ & 100 & 100 & 100 & 100 & 40 & 80 & 40 & 90 & 100 & 80 \\
\hline & Média & 68,72 & 72,71 & 93,62 & 83,64 & 48,62 & 72,96 & 62,34 & 69,50 & 73,60 & 66,06 \\
\hline & Desvio padrão & 4,76 & 5,96 & 2,76 & 8,50 & 14,24 & 17,90 & 15,28 & 9,88 & 10,11 & 7,99 \\
\hline & Mediana & 70,30 & 71,40 & 92,80 & 83,65 & 39,90 & 70,05 & 57,90 & 69,00 & 74,00 & 68,25 \\
\hline \multirow{6}{*}{ 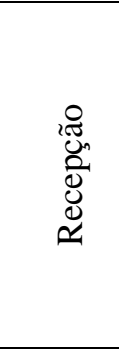 } & $\mathrm{N}^{0}$ total de aferições & 5 & 10 & 5 & 10 & 5 & 10 & 5 & 10 & 5 & 10 \\
\hline & $\begin{array}{l}\% \text { de temperatura } \\
<\operatorname{de~} 60^{\circ} \mathrm{c}^{\mathrm{b}+(2,8)}\end{array}$ & 20 & 0 & 0 & 0 & 80 & 30 & 60 & 20 & 80 & 50 \\
\hline & $\begin{array}{l}\% \text { de temperatura } \\
\geq \text { de } 60^{\circ} \mathrm{c}^{\mathrm{b}-(-2,8)}\end{array}$ & 80 & 100 & 100 & 100 & 20 & 70 & 40 & 80 & 20 & 50 \\
\hline & Média & 67,64 & 73,59 & 89,16 & 81,80 & 45,80 & 73,43 & 59,36 & 65,50 & 57,68 & 60,29 \\
\hline & Desvio padrão & 7,83 & 5,93 & 3,07 & 6,16 & 9,64 & 15,91 & 15,78 & 10,51 & 4,21 & 6,76 \\
\hline & Mediana & 72 & 73,90 & 89 & 80,70 & 43 & 74,90 & 51,70 & 65,90 & 55,90 & 61,10 \\
\hline \multirow{4}{*}{ 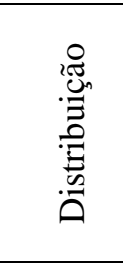 } & $\mathrm{N}^{0}$ total de aferições & 15 & 30 & 15 & 30 & 15 & 30 & 15 & 30 & 13 & 30 \\
\hline & $\begin{array}{l}\% \text { de temperatura } \\
<\operatorname{de~} 60^{\circ} \mathrm{c}^{\mathrm{b}+(2,8)}\end{array}$ & 46,67 & 40 & 0 & 6,67 & 86,67 & 43,33 & 40 & 10 & 38,46 & 73,33 \\
\hline & $\begin{array}{c}\% \text { de temperatura } \\
\geq \operatorname{de} 60^{\circ} \mathrm{c}^{\mathrm{b}-(-2,8)}\end{array}$ & 53,33 & 60 & 100 & 93,33 & 13,33 & 56,67 & 60 & 90 & 61,54 & 26,67 \\
\hline & Média & 60,46 & 63,84 & 78,31 & 71,42 & 47,73 & 69,38 & 69,09 & 76,72 & 60,75 & 56,44 \\
\hline
\end{tabular}




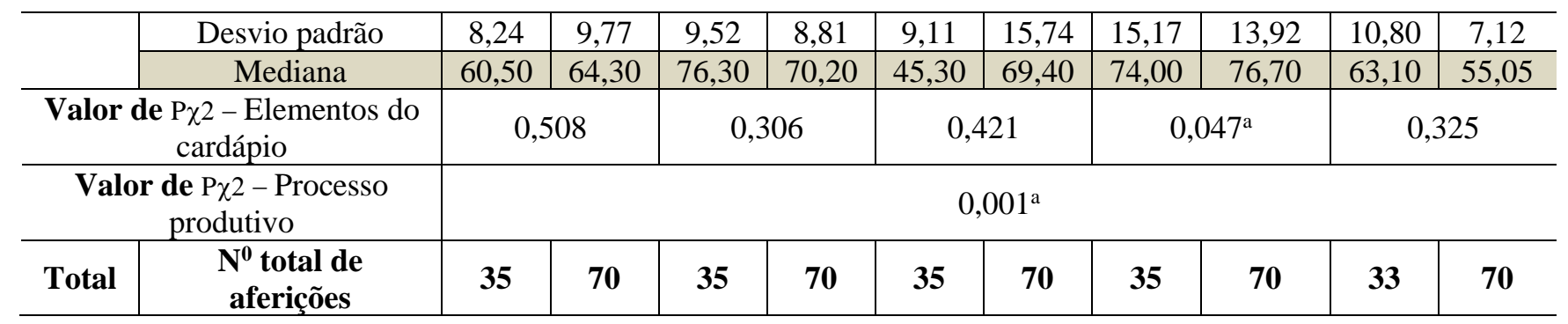

Faixa de temperatura segue as recomendações da CVS5/2013, para conformidade e inconformidade. Quando aparecer a letra $a=$ teste qui-quadrado significativo $(5 \%)$; $b+$ resíduos padronizados (Zres), valor positivo $\geq+1,96$; bresíduos padronizados (Zres), valor negativo $\leq-1,96$, ou seja, nível de significância de 5\%.

Estes achados ressaltam a importância do controle do tempo e da temperatura das refeições produzidas. Desta forma, é de fundamental importância atender ao que preconiza a RDC n²16 (BRASIL, 2004), que determina que os alimentos quentes devem ser mantidos acima de $60^{\circ} \mathrm{C}$ por até seis horas contados a partir do momento que o fogo é desligado.

Ao longo do ciclo produtivo as preparações vão perdendo temperatura, fato que pode estar associado ao longo tempo de espera entre o término da cocção até o momento da distribuição; condições dos equipamentos utilizados para armazenamento até o momento em que as refeições sejam transportadas; condições climáticas do ponto de distribuição, pois a UAN localizava-se próximo ao mar e sofria incidência do vento, sobretudo na área da distribuição, contribuindo para maior dificuldade em manter a temperatura dos alimentos.

Todavia, a média de temperatura das refeições da cadeia aquecida nos ciclos da produção, espera, envase e distribuição estavam acima dos $60^{\circ} \mathrm{C}$, o que contribui para garantir a segurança alimentar das refeições transportadas (Tabela 2). Entretanto, vale ressaltar que em alguns momentos a guarnição era a preparação que mais se encontrava em desacordo com relação à temperatura.
$\mathrm{Na}$ etapa da recepção da carga foi observada média de temperatura abaixo de $60^{\circ} \mathrm{C}$ para a guarnição, prato principal e opção no primeiro período do estudo. O desvio de temperatura da guarnição iniciou-se no processo do envase e continuou até a distribuição. Essa inadequação não foi observada no segundo período do estudo, indicando que a Unidade realizou medida corretiva para este problema.

Avaliando-se a frequência relativa, é observado que a guarnição começou a ter crescimento na frequência de temperaturas em inconformidade com o preconizado, onde no momento da produção $40 \%$ foi o valor máximo, chegando até $86,67 \%$ de inconformidades na fase de distribuição. $\mathrm{O}$ mesmo pôde ser observado com o prato principal, em que o percentual de temperaturas fora do recomendado variou de $40 \%$ no momento da produção e distribuição, chegando ao máximo de $60 \%$ no momento da espera, envase e recepção da carga. Com a opção não foi diferente, pois no momento da recepção da carga na primeira realização do estudo, a mesma encontrou-se com $80 \%$ de irregularidade na temperatura, enquanto que no momento da distribuição, na pesquisa seguinte, sua inadequação chegou a 73,33\% (Tabela 2).

Os valores de inadequação da guarnição podem estar associados às dificuldades de planejar um cardápio para refeições transportadas, quando se opta 
por um cardápio com preparações com menor quantidade de água, a exemplo de farofa e macarrão, além das várias alterações que os alimentos podem sofrer quando transportados (SOUZA; SPINELLI; MATIAS, 2016). Resultado semelhante foi encontrado em um estudo realizado por Penedo et al., (2015), onde a temperatura do macarrão de todos os restaurantes analisados estava inadequada, apesar de permanecer acima de $50^{\circ} \mathrm{C}$.

Quando comparados os dados da guarnição do primeiro para o segundo período estudado percebe-se que na produção houve, respectivamente, declínio de 70,40 (22,04 Dp) para 69,34 (21,72 Dp) na média das temperaturas, porém na espera, recepção e distribuição às temperaturas no segundo período do estudo foram maiores, com um maior percentual de conformidade, mesmo assim não foram observadas diferenças estatisticamente significativas ao nível de $5 \%$ pelo teste qui-quadrado.

Esses achados podem ser associados a falhas dos equipamentos pass-throughs e balcão térmico. Contudo, observou-se que as temperaturas médias dos pass-throughs no segundo período foram maiores (62\%), contribuindo para maiores médias de temperaturas dos alimentos neles acondicionados. Vale destacar que são observadas no balcão de $\begin{array}{llllll}\text { distribuição aquecido } & 1 & \left(350^{\circ} \mathrm{C}\right) & \text { e } & 2 & \left(200^{\circ} \mathrm{C}\right)\end{array}$ temperaturas muito elevadas dos equipamentos, o que indica que os mesmos poderiam estar descalibrados ou que houve erro de aferição da temperatura (Gráfico $1)$.

O prato principal, composto por preparações a base de carnes, também foi observada inadequação de temperaturas em todas as fases do ciclo produtivo e em ambos os períodos do estudo, sobretudo, no primeiro período que tiveram maiores frequências de inconformidade da temperatura, fato que levou a diferenças significativas, refletida na etapa da produção e distribuição, ambos com $40 \%$ de temperatura abaixo do preconizado pela CVS5 (SÃO PAULO, 2013).

Os fatores que podem ter contribuído para estes achados são os tipos de preparações que favorecem perda de calor por sua menor quantidade de água, e a maior superfície de contato como bifes sem molhos, peixe empanado, pernil, entre outras preparações servidas na unidade ou ainda pelo início precoce da cocção de algumas preparações ou o tempo prolongado de exposição do alimento a temperatura ambiente.

Resultados semelhantes foram observados por Penedo et al., (2015) na avaliação das temperaturas dos alimentos durante o preparo e distribuição em restaurantes comerciais, onde a temperatura do bife mostrou-se inadequada em um restaurante e por Meneses, Ribeiro e Monteiro (2017), que encontraram a média de temperatura para o prato principal de $58,88^{\circ} \mathrm{C}, 55,38^{\circ} \mathrm{C}$ e $59,84^{\circ} \mathrm{C}$, do primeiro ao terceiro dia avaliados, respectivamente em um restaurante comercial de Belo Horizonte.

É possível perceber que houve melhora significativa de um período para o outro em todo o ciclo produtivo avaliado, principalmente no momento da distribuição, fato que pode estar associado aos equipamentos utilizados para a manutenção da temperatura dos alimentos.

$\mathrm{O}$ arroz apresentou conformidade na recepção durante o primeiro estudo $(80 \%)$ e na distribuição $(53,33 \%$ no primeiro estudo e $60 \%$ no segundo estudo), ou seja, estavam com temperaturas em conformidade até o envase (100\%), e que foram sendo perdidas a partir desta fase. A redução desta adequação pode ter se dado pelo tempo de espera para o fechamento dos hotbox que ocorre somente depois 
da pesagem de todas as preparações que serão transportadas. Portanto, indica-se a necessidade de mudanças no procedimento.

De acordo com a RDC n ${ }^{\circ} 12$ (BRASIL, 2001), que estabelece os padrões microbiológicos sanitários para alimentos, quando cozido, o arroz favorece o crescimento de Bacillus cereus e coliformes termotolerantes a $45^{\circ} \mathrm{C}$, respectivamente. $\mathrm{O}$ risco patológico do Bacillus cereus está relacionado à produção de toxinas produzidas pela própria bactéria. $\mathrm{O}$ risco patológico dos termotolerantes apresenta-se por diarreia, dores abdominais, vômitos, febre e náuseas. As intoxicações ocorrem mediante conservação inadequada do alimento e falhas no controle do tempo e temperatura (SILVA JR, 2014).

Vale informar que a cocção do mesmo começa ainda no período da manhã, após o término o mesmo permanece no caldeirão até ser retirado e colocado nos gastronorm onde são armazenados nos pass-throughs. Todo processo entre o término da cocção até o armazenamento leva em média duas horas (Quadro 2). É importante destacar que com relação ao tempo dispendido no processo produtivo do arroz observa-se que mudanças substanciais foram realizadas entre os anos de 2014 e 2015, tendo em vista que houve uma diminuição em 122 minutos para finalizar todo o processo.

Ressalta-se que antes de iniciar a segunda coleta (em 2015), foi realizado a troca dos caldeirões da UAN, no entanto, observou-se no segundo período uma média de temperatura menor quando comparado os estudos e essa diferença é observada também nas temperaturas do feijão e da guarnição demonstrando a necessidade de concertos no utensílio.

No envase, recepção da carga e distribuição das refeições, quando comparado o primeiro período do estudo com o segundo percebeu-se que as temperaturas médias estavam maiores no segundo momento fato que pode estar associado à troca dos hotboxs utilizados no transporte das refeições, intervenção realizada após a coleta do primeiro estudo. Assim, é indispensável que o hotbox mantenha-se devidamente fechado durante o transporte de maneira a evitar perda de temperatura, além de apresentar-se integro e higienizado para impedir a contaminação do alimento. Além disso, no momento do transporte nos hotbox devem constar da identificação do produto, data de preparo e o prazo de validade (SILVA JR., 2014; BRASIL, 2004).

O feijão apresentou 100\% de conformidade do momento da produção até a distribuição na primeira fase do estudo, tendo um declínio insignificante em seu valor no momento da distribuição $(93,33 \%)$ na segunda fase da pesquisa. Esta foi a preparação que obteve o melhor índice de adequação. Dados similares foram obtidos no estudo realizado em Minas Gerais por Meneses, Ribeiro e Monteiro (2017). As explicações para tamanha adequação circundaram a maior aquosidade da preparação, fator que contribui para a manutenção da temperatura por maior período de tempo.

Quando comparados nas duas fases do estudo, a situação do feijão mostra-se similar à do arroz, pois o arroz apresentou menores média de temperatura apenas no momento do envase $(68,72 \mu)$, recepção da carga $(67,64 \mu)$ e distribuição da refeição $(60,46 \mu)$ no primeiro momento do estudo. No entanto, o arroz e o feijão apresentaram maior índice de adequação quando comparado com as demais preparações analisadas. Resultados semelhantes foram demonstrados por Nascimento et al., (2016) em uma Unidade de Alimentação e Nutrição de São Luís, onde estas preparações apresentaram média inicial e final dentro dos padrões exigidos pela legislação vigente. 
Com a opção ovolactovegetariana também houve declínio de temperatura na produção, recepção e distribuição na primeira coleta e de forma predominante durante todo ciclo na segunda tomada, chegando até $73,33 \%$ de temperatura em inconformidade. O tipo de preparação ofertada no cardápio não oferecia grande variedade, geralmente eram servidas panquecas, suflês, quiches, omeletes, tortas e jardineira de soja que necessitam de maior manipulação, perdendo temperatura desde o processo

De forma geral observou-se que o tempo médio dispendido no processo produtivo do arroz, prato principal e guarnição tiveram mudanças substanciais de forma positiva; indicando que a UAN inferiu alterações neste. Contudo, o feijão e opção tiveram seu tempo médio aumentado da produção à distribuição, indicando necessidade de rever o processo produtivo destes.

Cabe ressaltar que a CVS-5/2013 admite alimentos expostos com temperatura $<60^{\circ} \mathrm{C}$ até $1 \mathrm{~h}$. Um longo tempo de permanência das preparações quentes em temperaturas inadequadas torna $\mathrm{o}$ alimento mais susceptível à contaminação por microrganismos. Neste aspecto, a guarnição e o prato principal requerem atenção, visto que estão comprometidas em decorrência das baixas temperaturas encontradas.

\section{CONCLUSÃO}

Este estudo atendeu ao objetivo de analisar o binômio tempo-temperatura, mostrando a importância de tal monitoramento em refeições transportadas, demonstrando que é possível avaliar as situações de riscos em tal modalidade de distribuição de refeições, sugerir e adotar medidas corretivas e posteriormente verificar a eficácia de tais medidas na Segurança Alimentar. de montagem até o final da distribuição. Além disso, o balcão térmico do segundo estudo também apresentou valores de temperaturas menores o que pode ter influenciado na manutenção da temperatura das refeições nele acomodado (Gráfico 1).

Borges et al., (2016), divergente do presente estudo, encontraram que a opção vegetariana teve a maior adequação de temperatura da cocção à distribuição, tanto no jantar quanto no almoço.

Os resultados demonstram inconformidades nas temperaturas dos alimentos em todo ciclo produtivo, mesmo obtendo pequenas melhorias do primeiro para o segundo período. A cadeia fria demonstra maior preocupação, pois apresentou larga inconformidade com as legislações em vigência. Já na cadeia aquecida, preparações como guarnição e o prato principal apresentaram resultados satisfatórios quando comparados de um período para o outro.

Mesmo assim ainda são necessárias medidas corretivas, que devem levar em consideração a composição das preparações, mostrando que este é um desafio para os responsáveis técnicos pelo serviço, tendo em vista a necessidade de flexibilizarem o processo produtivo quando deparados com preparações com menor atividade de água, as quais merecem especial atenção.

\section{AGRADECIMENTO}

Agradecemos ao Núcleo de Segurança Alimentar da Universidade em estudo que era responsável pela fiscalização do Restaurante Universitário e nos deu apoio durante toda a realização do estudo.

Todos os autores declararam não haver qualquer potencial conflito de interesses referente a este artigo. 


\section{REFERÊNCIAS}

ABREU, E.S.; SPINELLI, M.G.N.; PINTO, A.M.S. Gestão de Unidades de Alimentação e Nutrição: um modo de fazer. 6 ed. São Paulo: Editora Metha, 2016 .

ASSOCIAÇÃO BRASILEIRA DAS EMPRESAS DE REFEIÇÕES COLETIVAS. Manual ABERC de Práticas de Elaboração e Serviço de Refeições para Coletividades. $11^{\mathrm{a}}$ ed. São Paulo: ABERC; 2015. 219 p.

BORGES, N.R.; MOURA, B.A.; VIEIRA, C.F.S. et al. Avaliação do binômio tempo-temperatura das refeições de um restaurante na cidade de PalmasTocantins. Revista Desafios, v.03, n.02, 2016.

BRASIL. Agência Nacional de Vigilância Sanitária. Resolução RDC no 12, de 2 de janeiro de 2001. Aprova Regulamento Técnico sobre Padrões Microbiológicos para alimentos. Brasília: Diário Oficial da República Federativa do Brasil. 2001.

BRASIL. Agência Nacional de Vigilância Sanitária. Resolução RDC no 216, de 15 de setembro de 2004. Dispõe sobre regulamento técnico de boas práticas para serviços de alimentação. Brasília: Diário Oficial da República Federativa do Brasil. 2004; 16 set.

MARINHO, G.A.; OLIVEIRA, G.S.; LIMA, J.L.; et al. Perfil epidemiológico das Doenças Transmitidas por Alimentos e seus fatores causais na região da Zona da Mata Sul de Pernambuco. UNOPAR Cient Ciênc Biol Saúde, v.17, n.4, p.23843, 2015.

MENESES, N.V.; RIBEIRO, R.C.; MONTEIRO, M.R.P. Análise das temperaturas dos alimentos na distribuição em um restaurante comercial no município de Belo Horizonte/MG. Nutrição Brasil, v.16, n.1, p.37-42, 2017.

NASCIMENTO, A.R.; REIS, A.C.; SOUSA, M.R.; SANTOS, S.J.L. Avaliação da temperatura de refeições transportadas na modalidade self service em São Luis - MA. Higiene Alimentar, v.30, n²60/261, Setembro/Outubro, 2016.

PENEDO, A.O.; JESUS, R.B.; SILVA, S.C.F. et al. Avaliação das temperaturas dos alimentos durante o preparo e distribuição em restaurantes comerciais de Belo Horizonte-MG. DEMETRA, v.10, n.2, p.429440, 2015.
SANTOS, V.F.N.; BASSI, S.M. Avaliação da temperatura dos equipamentos e alimentos servidos em unidades de alimentação e nutrição na cidade de São Paulo. Linkania Revista Científica, v.5, n.1, p.110-125, 2015.

SÃO PAULO. Secretaria de Estado da Saúde. Portaria CVS 5 de 09 de abril de 2013. Aprova o regulamento técnico sobre boas práticas para estabelecimentos comerciais de alimentos e para serviços de alimentação. São Paulo: Diário Oficial de São Paulo. 2013.

SÃO PAULO. Secretaria Municipal da Saúde. Manual de boas práticas de manipulação de alimentos. São Paulo: Prefeitura do município de São Paulo; 2016.

SILVA Jr, E.A. Manual de controle higiênicosanitário em serviços de alimentação. $7^{\circ}$ ed. São Paulo: Varela; 2014.

SOUZA, C.K.S.; SPINELLI, M.G.N.; MATIAS, A.C.G. Temperaturas das dietas de pacientes servidas em um hospital. Revista Univap, São José dos Campos, v.22, n.39, jul.2016.

WIETHÖLTER, M.J.; FASSINA, P. Temperaturas de armazenamento e distribuição dos alimentos. Segurança Alimentar e Nutricional, Campinas, v.24, n.1, p.17-25, 2017. 